\title{
PENGEMBANGAN MULTIMEDIA INTERAKTIF UNTUK MENINGKATKAN HASIL BELAJAR SISWA PADA KOMPETENSI DASAR STABILITY FLIGHT AND DYNAMICS SISWA SMK
}

\author{
Ana N. Octaviani ${ }^{1}$, Enda Permana ${ }^{2}$ Yayat $^{3}$ \\ Universitas Pendidikan Indonesia \\ Jl. Dr. Setiabudhi No. 229 Bandung 40154 \\ anaoctvn@gmail.com
}

\begin{abstract}
ABSTRAK
Penelitian ini bertujuan untuk menghasilkan multimedia interaktif yang sesuai dan berkriteria baik yang diharapkan dapat meningkatkan hasil belajar siswa pada kompetensi dasar Stability Flight and Dynamics. Penelitian ini dilakukan mengingat hasil belajar siswa yang kurang baik, materi pembelajaran yang bersifat abstrak, kurangnya bimbingan dari guru saat proses pembelajaran, dan belum memadainya referensi belajar yang dimiliki siswa. Metode penelitian yang digunakan adalah metode penelitian dan pengembangan (research and development). Subjek penelitian pada uji coba terbatas adalah satu kelas yaitu kelas X TPU (Teknologi Pesawat Udara) 7 di SMK Negeri 12 Bandung. Temuan dari penelitian ini adalah: 1) Multimedia yang dihasilkan dikembangkan berdasarkan hasil analisis pengguna, analisis materi, analisis perangkat lunak, dan analisis perangkat keras yang akan digunakan. Hasil analisis kemudian dikemas menjadi desain multimedia berupa flowchart, storyboard, dan soal evaluasi. Desain dikembangkan menjadi antarmuka yang terdiri dari tujuh laman utama dan coding untuk memberikan perintah pada tiap laman. Multimedia yang telah dikembangkan divalidasi oleh ahli media dan ahli materi, jika dinyatakan layak maka dilakukan uji lapangan untuk mengetahui respon dan peningkatan hasil belajar pengguna setelah menggunakan multimedia. Data hasil validasi dan uji lapangan diolah sehingga dapat disimpulkan multimedia layak digunakan. 2) terdapat peningkatan hasil belajar siswa setelah menggunakan multimedia pembelajaran interaktif pada kompetensi dasar stability flight and dynamics
\end{abstract}

Kata kunci: multimedia interaktif, hasil belajar, stability flight, dynamics

\section{PENDAHULUAN}

Aerodynamics and Flight Control (AFC) adalah salah satu mata pelajaran dalam kelompok mata pelajaran C2 (Program Bidang Keahlian) pada program keahlian Teknologi Pesawat Udara. Mata pelajaran ini diperlukan sebagai dasar pemahaman mengenai aircraft system pada jurusan airframe powerplant dan sebagai acuan untuk melanjutkan materi ke tingkatan yang lebih tinggi. Pada mata pelajaran ini siswa dituntut untuk berpikir tinggi, karena siswa dituntut untuk paham mengenai hal-hal yang tidak terlihat nyata namun sebenarnya ada. Salah satu kompetensi dasar pada mata pelajaran aerodynamics and flight control ini adalah stability flight and dynamic. Kompetensi dasar ini memiliki materi yang seluruhnya memerlukan pemikiran yang tinggi.

\footnotetext{
1 Mahasiswa Departemen Pendidikan Teknik Mesin FPTK, UPI

2 Dosen Departemen Pendidikan Teknik Mesin FPTK, UPI

3 Dosen Departemen Pendidikan Teknik Mesin FPTK, UPI
} 
Hasil observasi awal, terhadap beberapa siswa Kelas X di SMK Negeri 12 Bandung yang mengikuti pelajaran Aerodynamics and Flight Control yang diambil secara acak. Terdapat beberapa kendala yang memengaruhi hasil belajar siswa pada kompetensi stability flight and dynamics. Pertama, dari konten pembelajaran stability flight and dynamics materi yang dibahas dalam kompetensi dasar ini bersifat abstrak sehingga siswa harus dapat memvisualisasikan ke dalam bentuk nyata. Kedua, dari proses pembelajaran dikelas, guru hanya memberikan judul bab dan siswa diminta untuk mencari tahu sendiri materi tersebut serta mempresentasikannya secara mandiri (tanpa didampingi). Akibatnya, tidak sedikit siswa yang cenderung acuh terhadap materi yang dipelajari. Ketiga, referensi belajar untuk siswa masih belum memadai. Keempat, dari segi teknologi, media yang digunakan belum sepenuhnya memfasilitasi siswa untuk memahami kompetensi dasar stability flight and dynamics, pembelajaran masih mengandalkan media yang dibuat dan sampaikan oleh siswa. Selain itu, hasil belajar dari kompetensi dasar ini masih sangatlah rendah.

Hasil studi pendahuluan, kelulusan di SMK Negeri 12 adalah yang mendapatkan nilai dengan predikat B, siswa yang belum lulus pada kelas TPU 3 mencapai 28 orang atau 80\%, dan pada kelas TPU 10 mencapai 29 orang atau $87.8 \%$, sehingga sebanyak $83.9 \%$ siswa dari kedua tersebut belum lulus dari kriteria ketuntasan minimal. Beberapa kendala yang memengaruhi terhadap rendahnya hasil belajar siswa pada kompetensi dasar stability flight and dynamics di SMK Negeri 12 Bandung, upaya yang dapat dilakukan untuk mengatasi permasalahan tersebut diantaranya dalam proses pembelajaran kompetensi dasar ini dibutuhkan media yang mampu mengatasi kendala-kendala yang telah dipaparkan sebelumnya.

Media yang digunakan harus disesuaikan dengan tujuan pembelajaran, bahan pembelajaran, kemudahan menggunakan media yang digunakan baik oleh guru ataupun siswa. Hal lain dalam penggunaan media adalah menyesuaikan kemampuan berpikir siswa dengan tahapan berpikir dimulai dari konkrit menuju abstrak, atau dari sederhana menuju kompleks. Diharapkan, penggunaan media dapat mengkonkritkan hal-hal yang abstrak dan hal-hal yang kompleks dapat disederhanakan.

Media pembelajaran yang akan dikembang adalah berupa multimedia interaktif model tutorial. Media model ini dikembangkan sebagai alat bantu yang dapat menunjang siswa dalam penguasaan materi dan siswa dapat memvisualisasikan proses aerodinamis dari pesawat sehingga konsep mudah dimengerti dan menarik untuk dipelajari. Multimedia interaktif model 
tutorial dipilih karena dapat merangsang belajar siswa secara mandiri dan diakhiri dengan mengerjakan latihan soal yang hasilnya dapat diketahui oleh siswa sehingga materi yang kurang dipahami dapat dipelajari lebih mendalam. Selain itu dengan menggunakan multimedia interaktif ini, siswa diharapkan dapat belajar mandiri meskipun tidak didampingi guru (Sanjaya, 2010).

\section{METODE PENELITIAN}

Penelitian ini menggunakan metode penelitian research and development $(\mathrm{R} \& \mathrm{D})$. Metode penelitian ini, digunakan untuk menghasilkan produk tertentu, dan menguji keefektifan produk tersebut. Produk yang dimaksud dalam penelitian ini adalah multimedia interaktif yang digunakan untuk memudahkan proses belajar mengajar. Penelitian ini dilakukan untuk menghasilkan produk yang sesuai pembelajaran serta berkriteria baik dan siswa mengalami peningkatan hasil belajar setelah menggunakan produk ini.

\section{HASIL PENELITIAN}

Pengembangan multimedia pembelajaran interaktif diperlukan beberapa tahapan yang harus dilakukan diantaranya tahap studi pendahuluan, tahap desain produk, tahap pengembangan multimedia, tahap validasi, tahap uji lapangan, dan tahap pengolahan data hasil uji. Validasi yang dilakukan oleh ahli media lebih menekankan pada tampilan antarmuka baik secara visual maupun audio, berikut hasil validasi multimedia oleh ahli media:

Tabel 1. Hasil Pengujian Ahli Media

\begin{tabular}{|c|c|c|c|c|c|c|c|}
\hline \multirow[b]{2}{*}{ No. } & \multirow[b]{2}{*}{ Aspek } & \multirow{2}{*}{$\begin{array}{l}\text { Jumlah } \\
\text { Butir }\end{array}$} & \multirow{2}{*}{$\begin{array}{l}\text { Skor } \\
\text { Ideal }\end{array}$} & \multicolumn{3}{|c|}{ Perolehan Skor } & \multirow[b]{2}{*}{$\%$} \\
\hline & & & & $\begin{array}{l}\text { Penguji } \\
\text { I }\end{array}$ & $\begin{array}{l}\text { Penguji } \\
\text { II }\end{array}$ & Rata-rata & \\
\hline \multirow[t]{2}{*}{1.} & Rekayasa & & & & & & \\
\hline & $\begin{array}{l}\text { Perangkat } \\
\text { Lunak }\end{array}$ & 7 & 28 & 25 & 22 & 23,5 & 83,92 \\
\hline \multirow[t]{2}{*}{2.} & $\begin{array}{l}\text { Komunikasi } \\
\text { Visual }\end{array}$ & 11 & 44 & 39 & 35 & 37 & 84.1 \\
\hline & \multicolumn{6}{|c|}{ Rata-rata } & 84,01 \\
\hline
\end{tabular}


Validasi yang dilakukan oleh ahli materi lebih menekankan pada konten atau isi multimedia seperti materi dan evaluasi yang disesuaikan dengan silabus. Hasil pengujian dapat dilihat pada tabel 2 berikut ini:

Tabel 2. Hasil Uji Ahli Materi

\begin{tabular}{|c|c|c|c|c|c|c|c|}
\hline \multirow{2}{*}{ No. } & \multirow{2}{*}{ Aspek } & \multirow{2}{*}{$\begin{array}{c}\text { Jumlah } \\
\text { Butir }\end{array}$} & \multirow{2}{*}{$\begin{array}{l}\text { Skor } \\
\text { Ideal }\end{array}$} & \multicolumn{3}{|c|}{ Perolehan Skor } & \multirow[b]{2}{*}{$\%$} \\
\hline & & & & $\begin{array}{c}\text { Penguji } \\
\text { I }\end{array}$ & $\begin{array}{l}\text { Penguji } \\
\text { II }\end{array}$ & Rata-rata & \\
\hline 1. & Pembelajaran & 14 & 56 & 56 & 53 & 54,5 & 97 \\
\hline 2. & Substansi & 4 & 16 & 16 & 16 & 16 & 100 \\
\hline \multicolumn{7}{|c|}{ Rata-rata } & 98,5 \\
\hline
\end{tabular}

Selain melakukan validasi terhadap ahli, peneliti melakukan respon terhadap pengguna. Respon ini dilakukan setelah sampel menggunakan multimedia interaktif. Hasil respon siswa terhadap multimedia dapat dilihat pada tabel 3 berikut ini:

\begin{tabular}{llccccc}
\multicolumn{7}{c}{ Tabel 3. Hasil Respon Siswa } \\
\hline No. & \multicolumn{1}{c}{ Aspek } & $\begin{array}{c}\text { Jumlah } \\
\text { Butir }\end{array}$ & $\begin{array}{c}\text { Skor } \\
\text { Ideal }\end{array}$ & $\begin{array}{c}\text { Jumlah } \\
\text { Responden }\end{array}$ & $\begin{array}{c}\text { Perolehan Skor } \\
\text { (rata-rata) }\end{array}$ & $\%$ \\
\hline 1. & Aksesbilitas & 4 & 16 & 31 & 13,54 & 84,62 \\
2. & $\begin{array}{l}\text { Motivasi } \\
\text { 3. }\end{array}$ & 3 & 12 & 31 & 10,87 & 90,58 \\
& $\begin{array}{l}\text { Aspek Pembelajaran } \\
\text { (Learning Goal Aligment) }\end{array}$ & 4 & 16 & 31 & 13,74 & 85.87 \\
4. & $\begin{array}{l}\text { Desain Tampilan } \\
\text { (Presentation Design) }\end{array}$ & 4 & 16 & 31 & 13,32 & 83,25 \\
\hline \multicolumn{7}{l}{ Rata-rata } \\
\hline
\end{tabular}

Hasil pengujian data hasil belajar pengguna dengan menggunakan statistik:

Tabel 4. Hasil Data Pre-test dan Post-test

\begin{tabular}{lccc}
\hline & Pre-test & Post-test & N-Gain \\
\hline Jumlah & 1515,79 & 2473,68 & 19,44 \\
Rata-rata & 48,9 & 79,8 & 0,63 \\
Nilai Minimal & 15,79 & 36,84 & -0.2 \\
Nilai Maksimal & 84,21 & 100 & 1 \\
Standar Deviasi & 18,39 & 17,62 & 0,3 \\
Varians & 338,3 & 310,42 & 0,09 \\
\hline
\end{tabular}

\section{PEMBAHASAN}

Tahap studi pendahuluan yang dilakukan terbagi menjadi studi lapangan dan studi literatur. Studi lapangan dilakukan agar peneliti mengetahui masalah yang dialami dan kriteria pembelajaran yang harus dicapai dilapangan. Setelah dilakukan wawancara kepada beberapa 
siswa yang telah belajar mengenai flight stability and dynamics kendala yang dialami adalah, siswa cenderung kurang mengerti dengan materi yang disampaikan oleh guru karena sumber yang tersedia belum cukup memadai, proses pembelajaran cenderung membosankan dan kurang efektif karena siswa diharuskan mempresentasikan materi yang didapat oleh kelompoknya tetapi tidak didampingi oleh guru, dan media yang digunakan belum cukup untuk mempresentasikan mengenai materi yang sifatnya abstrak.

Tahap desain produk, pertama harus membuat rancangan kerja yang harus dilakukan dan diperlukan sebelum memulai mengembangkan multimedia. Pada tahap ini, data-data yang didapat baik dari lapangan maupun dari studi literatur dijadikan acuan peneliti untuk membuat flowchart, storyboard, dan soal pemahaman.

Pada tahap pengembangan media, ada beberapa tahapan yang dilakukan peneliti. Pertama peneliti membuat antarmuka multimedia mengacu pada rancangan storyboard yang telah dibuat pada tahap desain. Setelah membuat tampilan antarmuka, dilakukan pengodean (coding). Tahap pengodean ini dilakukan dengan tujuan untuk menjalankan fungsi fitur-fitur yang ada pada multimedia, seperti button, dan animasi. Pengodean menggunakan Action Script 3.0.

Validasi ahli dilakukan untuk mengetahui kelayakan multimedia yang telah dikembangkan. Validasi ahli ini terdiri dari ahli media dan ahli materi dengan menggunakan angket yang terdiri dari beberapa aspek penilaian. hasil pengujian multimedia oleh ahli media diperoleh rata-rata presentasi kelayakan sebesar 84,0\% yang dikategorkan sangat layak. Validasi oleh ahli materi dapat dilihat hasil uji multimedia oleh ahli materi diperoleh rata-rata persentase kelayakan sebesar 98,5\% dikategorikan sangat layak.

Multimedia pembelajaran interaktif ini diimplementasikan dalam proses pembelajaran. Uji lapangan ini dilakukan pada kelas X TPU 7 dengan jumlah 31 siswa, dilaksanakan di laboratorium komputer, masing-masing siswa belajar dengan menggunakan satu komputer beserta perangkat headphone untuk mendengarkan audio yang tersedia pada multimedia. Setelah siswa melakukan pembelajaran dengan menggunakan multimedia, kemudian peneliti memberikan angket kepada siswa untuk mengetahui respon terhadap multimedia yang telah digunakan.

Hasil angket respon siswa terhadap multimedia pembelajaran interaktif pada tabel 3, diperoleh rata-rata prosentase keterpakaian multimedia oleh pengguna, yaitu sebesar 85,8\%, 
yang artinya bahwa multimedia interaktif yang dikembangkan mudah untuk dipakai dan dioperasikan oleh pengguna. Pengembangan multimedia, selain dilakukan penilaian respon terhadap multimedia, juga dilakukan tes untuk mengetahui peningkatan hasil belajar siswa dengan mencari $n$-gain dari hasil pre-test dan post-test.multimedia yang telah divalidasi oleh ahli diujikan pada pengguna, dalam penelitian ini pengguna adalah siswa.

Nilai rata-rata yang didapat sebelum penggunaan multimedia adalah sebesar 48,9 dan sesudah penggunaan media sebesar 79,8 dengan rata-rata (n-gain) sebesar 0,63 yang dapat dikategorikan bahwa peserta didik mengalami peningkatan hasil belajar yang dapat diketagorikan peningkatan sedang. Adapun setelah mencoba dalam proses pembelajaran siswa mendapatkan hasil belajar yang meningkat, yakni siswa mencapai tingkat ketuntasan belajar yang sesuai KKM yakni 67,74\% dan dibawah KKM 32,26 dengan nilai rata-rata 79,80. Hasil ini menunjukan bahwa penggunaan multimedia interaktif berbasis animasi dapat meningkatkan hasil belajar, karena pada sebelum pembelajaran siswa yang mencapai ketuntasan sesuai KKM hanya 16,1 \% sedangkan yang 83,9\% masih dibawah KKM.

Multimedia interaktif berbasis animasi mampu untuk meningkatkan hasil belajar dan menumbuhkan motivasi yang berlipat. Media pembelajaran dapat memperjelas penyajian pesan sehingga dapat memperlancar proses pembelajaran dan dapat meningkatkan hasil belajar (Arsyad, 2014). Tahapan-tahapan pengembangan multimedia tersebut peneliti ditemukan beberapa kekurangan dan kelebihan sebagai berikut:

1. Multimedia pembelajaran ini memungkinkan siswa untuk belajar mandiri dan memiliki alur yang jelas. Terdapat evaluasi yang memungkinkan siswa untuk mengukur mandiri pemahamannya terkait materi yang disampaikan. Tujuan pembelajaran multimedia model tutorial (Nandi, 2006):

a. Untuk meningkatkan penguasaan dan pengetahuan para siswa sesuai dengan yang dimuat dalam modul-modul dan melakukan usaha-usaha pengayaan materi yang relevan.

b. Untuk meningkatkan kemampuan dan keterampilan siswa tentang cara memecahkan masalah, mengatasi kesulitan atau hambatan agar mampu membimbing diri sendiri.

c. Untuk meningkatkan kemampuan siswa tentang cara belajar mandiri dan menerapkannya dapa masing-masing modul yang dipelajari. 
2. Multimedia ini memvisualisasikan materi yang abstrak sehingga siswa lebih mudah memahami materi. Animasi yang ditampilkan sudah berbentuk 3D sehingga siswa lebih mudah memahami materi seperti sesuai dengan pesawat asli. Pengalaman belajar yang diperoleh siswa dapat melalui proses perbuatan atau mengalami sendiri apa yang dipelajari, proses mengamati dan mendengarkan melalui media tertentu dan proses mendengarkan melalui bahasa. Semakin konkret siswa mempelajari suatu hal, maka semakin banyaklah pengalaman yang diperoleh siswa. Sebaliknya, semakin abstrak siswa memperoleh pengalaman, maka semakin sedikit pengalaman yang akan diperoleh siswa (Sanjaya, 2010).

3. Mulmedia pembelajaran ini mudah digunakan karena dapat dioperasikan pada perangkat komputer berspesifikasi rendah ataupun tinggi.

Kekurangan dari multimedia yaitu: suara yang digunakan pada multimedia ini masih kaku atau kurang humanis; belum ada konten game atau flight simulator dan belum ada backsound selama multimedia berjalan; dan multimedia hanya dapat digunakan pada perangkat komputer/laptop. Sebaiknya dikembangkan sehingga bisa dioperasikan pada perangkat handphone agar memudahkan siswa dalam memperlajari materi yang ada.

\section{KESIMPULAN}

Kesimpulan penelitian ini, penggunaan multimedia interaktif dapat meningkatkan hasil belajar siswa pada kompetensi dasar stability flight and dynamics. Hal ini dapat dilihat dari peningkatan (gain) hasil belajar peserta didik.

\section{DAFTAR PUSTAKA}

Arsyad, A. (2014). Media Pembelajaran. Jakarta: Raja Grafindo Persada.

Nandi (2006). Penggunaan Multimedia Interaktif dalam Pembelajaran Geografi di Persekolahan. Jurnal GEA (6)1, hlm. 1-9.

Sanjaya, W. (2010). Perencanaan dan desain sistem pembelajaran. Jakarta: Kencana. 